\title{
Influence of Protease Inhibitors on Bond Degradation of Self-Etch Adhesive Systems to Caries-Affected Dentin: An in Vitro Study
}

\author{
Diana Roberta Pereira Grandizoli ${ }^{1}$, Sérgio Luiz Pinheiro ${ }^{2 *}$ \\ ${ }^{1}$ Health Sciences, Pontifícia Universidade Católica de Campinas (PUC-Campinas), São Paulo, SP, Brazil \\ ${ }^{2}$ Master's Program in Health Sciences, PUC-Campinas School of Dentistry. Campinas, São Paulo, SP, Brazil \\ Email: dianarobertapereira@hotmail.com, *slpinho@puc-campinas.edu.br
}

How to cite this paper: Grandizoli, D.R.P. and Pinheiro, S.L. (2018) Influence of Protease Inhibitors on Bond Degradation of SelfEtch Adhesive Systems to Caries-Affected Dentin: An in Vitro Study. Advances in Biological Chemistry, 8, 15-28.

https://doi.org/10.4236/abc.2018.81002

Received: January 12, 2018

Accepted: February 10, 2018

Published: February 13, 2018

Copyright (c) 2018 by authors and Scientific Research Publishing Inc. This work is licensed under the Creative Commons Attribution International License (CC BY 4.0).

http://creativecommons.org/licenses/by/4.0/

\begin{abstract}
Background: A decline in $\mathrm{pH}$ and dissolution of the inorganic content of the dental tissues are followed by exposure of the organic portion of the tooth, which, in dentin, is largely composed of collagen fibres. These unprotected fibres are then degraded by metalloproteinases and cysteine cathepsins, proteolytic enzymes present in dentin. We evaluated the influence of protease inhibitors on the bond strength of a self-etch adhesive system to caries-affected dentin. Eighty permanent third molars were selected for the study. Dentinal caries were induced artificially by the microbial method and the teeth were divided in four groups: G1-application of Clearfil SE Bond adhesive system (CL); G2-2\% chlorhexidine (CLX) + CL; G3-sodium bicarbonate (BIC) + CL; $\mathrm{G} 4-\mathrm{BI}+\mathrm{CLX}+\mathrm{CL}$. Bond strength was assessed immediately and at six months. During the six months, the specimens were stored in distilled water. Microtensile bond strength testing was performed. On immediate testing, there was no significant difference in bond strength across the control, BIC, and CLX groups. The combination of BIC + CLX, however, led to an immediate, significant reduction in bond strength. After six months, bond strength was reduced in all groups. The highest bond strength was obtained in the control group $(P<0.05)$. Most fractures were adhesive, both immediately and at six months. We concluded that the cavity pretreatment with $2 \%$ CLX or $2 \%$ BIC did not have an immediate negative impact on bond strength of the Clearfil SE Bond system. After specimens were stored for six months in water, their bond strength of specimens was reduced in all groups. This reduction was the greatest in the groups exposed to the inhibitors.
\end{abstract}

\section{Keywords}

Protease Inhibitors, Chlorhexidine, Sodium Bicarbonate, Microtensile Bond, 


\section{Introduction}

The dentinal caries plaque biofilm has a complex structure and produces acids that degrade the inorganic matrix of enamel, dentin, and cementum [1] [2] [3] [4] [5]. A decline in $\mathrm{pH}$ and dissolution of the inorganic content of the dental tissues are followed by exposure of the organic portion of the tooth, which, in dentin, is largely composed of collagen fibers. These unprotected fibers are then degraded by metalloproteinases and cysteine cathepsins, proteolytic enzymes present in dentin [6]-[11]. The adhesive system of choice must be hydrophilic enough to interact with the organic content of dentin and hydrophobic enough to interact with the composite resin [12].

The longevity of adhesive restorations may be compromised by the presence of metalloproteinases. Research has sought to characterize inhibitors of these enzymes. These include 2\% chlorhexidine and 17\% EDTA [13] [14]. Other inhibitors derived from natural sources have been evaluated for their antiproteolytic activity and fewer side effects as compared with synthetic substances. These include catechins (epigallocatechin gallate, EGCG) extracted from green tea or grapeseed extract [15] [16]. Sodium bicarbonate is a basic substance that can inactivate the cathepsin precursors of endogenous proteases, and could thus act as an indirect metalloproteinase inactivator [17]. Furthermore, it is biocompatible and readily available to dental practitioners.

Self-etching adhesive systems contain acid monomers in their composition. These adhesives systems are capable of forming chemical bonds with the calcium in hydroxyapatite. The stability of these bonds over time is greater than that of conventional adhesive systems, which require phosphoric acid etching prior to application [18]. Self-etch adhesive may be classified on the basis of $\mathrm{pH}$ as weak $(\mathrm{pH}>2)$, moderate $(1<\mathrm{pH}<2)$, or strong $(\mathrm{pH}<1)$ [19]. The weak self-etch adhesives containing the 10-MDP (10-methacryloyloxydecyl dihydrogen phosphate) monomer interact well with calcium in dental tissues increasing the total surface free energy as the surface roughness decreases [20]. MDP ionically bonds to hydroxyapatite through a nanolayer. This characteristic influences the ability of the adhesive system to interact with enamel and dentin [21] [22]. Within this context, the present study sought to assess the influence of protease inhibitors on the bond strength of weak self-etch adhesive systems. The null hypothesis is that there is no significant difference in bond strength of caries-affected dentin when using protease inhibitors.

\section{Materials and Methods}

The present study was approved by the Research Ethics Committee of PUCCampinas (protocol number 1.203.078). 


\subsection{Sample Selection}

Eighty unerupted permanent third molars were selected at the Dental Clinic of PUC-Campinas. The patients included were male and female and the ages ranged from 20 and 30 years.

Sample size calculation was performed by ANOVA, with a minimum difference between treatment means $=0.23$, standard error $=0.25$, number of treatments $=4$, and statistical power $=0.80$. The minimum number of teeth per group was thus calculated as 15.

The inclusion criteria were:unerupted permanent third molars with complete coronal and radicular formation observed in periapical radiography. The permanent third molars included didn't have done coronal section during extraction and after extraction, the teeth included didn't have visible cracks or fractures under 10X magnification.

The selected teeth were stored in $0.5 \%$ chloramine-T (LabCenter, São Paulo, Brasil) at $37^{\circ} \mathrm{C}$ up the begining of research (Marchesi et al., 2014) [20]. The occlusal surface of each specimen was ground down using a double-sided diamond disc (KG Sorensen, Cotia, Brazil) and sanded with silicon carbide papers of descending grit sizes (Norton, Guarulhos, Brazil) in a grinder/polisher (Buehler, Illinois, USA), under water-cooling, to obtain a flat dentin surface. Then, 120-grit and 240-grit sandpaper (Buehler, Illinois, USA) was used to expose the dentin. Finally, 400-grit paper (Buehler, Illinois, USA) was applied for 10 seconds, followed by 600-grit paper (Buehler, Illinois, USA) for 60 seconds, to create a standard smear layer [23].

\subsection{Induction of Carious Lesions}

The specimens were sealed with epoxy resin (Araldite, São Bernardo do Campo, Brazil) and nail polish (Colorama, São Paulo, Brazil) throughout, except for the dentin surface. The specimens were esterilizated. With the purpose of simulating caries-affected dentin, the teeth were placed in sterile test tubes with brain heart infusion (BHI) broth plus $0.5 \%$ yeast extract, $0.5 \%$ glucose, and $1 \%$ sucrose (all supplies obtained from LabCenter, São Paulo, Brazil). Streptococcus mutans type strain ATCC $^{\circledR} 25175^{\text {mit }}$ (Fundação André Tosello, Campinas, Brazil), standardized to 0.5 MacFarland turbidity, was added to the BHI medium. The samples were incubated at $37^{\circ} \mathrm{C}$ for 14 days in anaerobic jars with gas-generating envelopes (LabCenter, São Paulo, Brazil) in an atmosphere containing 85\% nitrogen $\left(\mathrm{N}_{2}\right), 10 \%$ carbon dioxide $\left(\mathrm{CO}_{2}\right)$, and $5 \%$ hydrogen $\left(\mathrm{H}_{2}\right)$, and stored in a bacteriological incubator. During this 14-day period, BHI broth (LabCenter) was replaced every 24 hours [24].

\subsection{Sample Groups}

Sterile curettes (SS White, Rio de Janeiro, Brazil) were used to remove infected dentin from all specimens. The criteria used for removal were those suggested by Banerjee and Schwendicke [25] [26] [27] who reported that infected (wet, sof- 
tened) dentin should be removed, while affected (dry, splintered) dentin should remain in the cavity. The smear layer of the remaining caries-affected dentin was created and standardized manually with 320 grain silicon carbide abrasive papers until hardened dentin, resistant to the touch of sharp exploratory probe, without using pressure, was obtained.

For bond strength testing, experimental groups were randomly divided (http://www.random.org) as follows $(n=20)$ (Table 1):

Group 1: Clearfil SE Bond adhesive system (Kuraray Noritake Dental; Sakazu, Kurashiki, Okayama, Japan), applied in accordance with manufacturer instructions.

Table 1. Composition and mode of application of the tested materials.

\begin{tabular}{|c|c|c|c|}
\hline Material & Primary components & $\mathrm{pH}$ & Mode of application \\
\hline $\begin{array}{l}\text { Clearfil SE Bond adhesive } \\
\text { system (Kuraray Noritake } \\
\text { Dental; Sakazu, Kurashiki, } \\
\text { Okayama, Japan) Batch } \\
\text { No. Primer: 9N0168 } \\
\text { Adhesive: 9U0269 }\end{array}$ & $\begin{array}{l}\text { Primer: } 10 \text {-MDP, HEMA, hydrophilic methacrylate, } \\
d l \text {-camphorquinone, } N, N \text {-dihydroxyethyl- } p \text {-toluidine, } \\
\text { water. Bond: } 10 \text {-MDP, bis-GMA, HEMA, hydrophobic } \\
\text { methacrylate, } d l \text {-camphorquinone, } \\
N, N \text {-dihydroxyethyl- } p \text {-toluidine, silanized colloidal silica }\end{array}$ & 2.0 & $\begin{array}{l}\text { 1) Active application of primer to the } \\
\text { dry dentin surface for } 20 \mathrm{~s} \\
\text { 2) Gentle air-jet drying for } 5 \mathrm{~s} \\
\text { 3) Application of bonding agent } \\
\text { 4) Gentle air-jet drying for } 5 \mathrm{~s} \\
\text { 5) Light-curing for } 10 \mathrm{~s}\end{array}$ \\
\hline $\begin{array}{l}\text { Sodium bicarbonate } \\
\text { (Biodinâmica Química e } \\
\text { Farmacêutica LTDA; } \\
\text { Ibiporã, Paraná, Brazil) } \\
\text { Batch No.: } 321 / 15\end{array}$ & Sodium bicarbonate $\left(\mathrm{NaHCO}_{3}\right)$ and flavouring agents & 8.0 & $\begin{array}{l}\text { Dilution: } 200 \mathrm{mg} \text { sodium bicarbonate } \\
\text { in } 10 \mathrm{~mL} \text { normal saline } \\
\text { 1) Active application to the dry dentin } \\
\text { surface for } 60 \mathrm{~s} \\
\text { 2) Removal of excess solution }\end{array}$ \\
\hline $\begin{array}{l}\text { Chlorhexidine (FGM } \\
\text { Dentscare LTDA; Joinville, } \\
\text { Santa Catarina, Brazil) } \\
\text { Batch No.: } 050815\end{array}$ & $\begin{array}{l}2 \% \text { chlorhexidine digluconate, deionized water, volatile } \\
\text { surfactant }\end{array}$ & $5.5-7$ & $\begin{array}{l}\text { 1) Active application to the dry dentin } \\
\text { surface for } 60 \mathrm{~s} \\
\text { 2) Removal of excess solution }\end{array}$ \\
\hline $\begin{array}{l}\text { Filtek Z350 XT (3M ESPE; } \\
\text { St Paul, MN, USA) Batch } \\
\text { No.: } 1535700494\end{array}$ & $\begin{array}{l}\text { Silane-treated ceramic filler, bisphenol A-glycidyl } \\
\text { methacrylate (bis-GMA), bisphenol A-polyethylene glycol } \\
\text { diether dimethacrylate (bis-EMA), silane-treated silicon } \\
\text { dioxide filler, silane-treated silica/zirconia filler, } \\
\text { diurethane dimethacrylate, polyethylene glycol } \\
\text { dimethacrylate, triethylene glycol dimethacrylate } \\
\text { (TEG-DMA), 2,6-di-tert-butyl-p-cresol (BHT), pigments }\end{array}$ & - & $\begin{array}{l}\text { 1) Composite resin build-up } \\
\text { technique } \\
\text { 2) Light-curing for } 40 \mathrm{~s}\end{array}$ \\
\hline
\end{tabular}
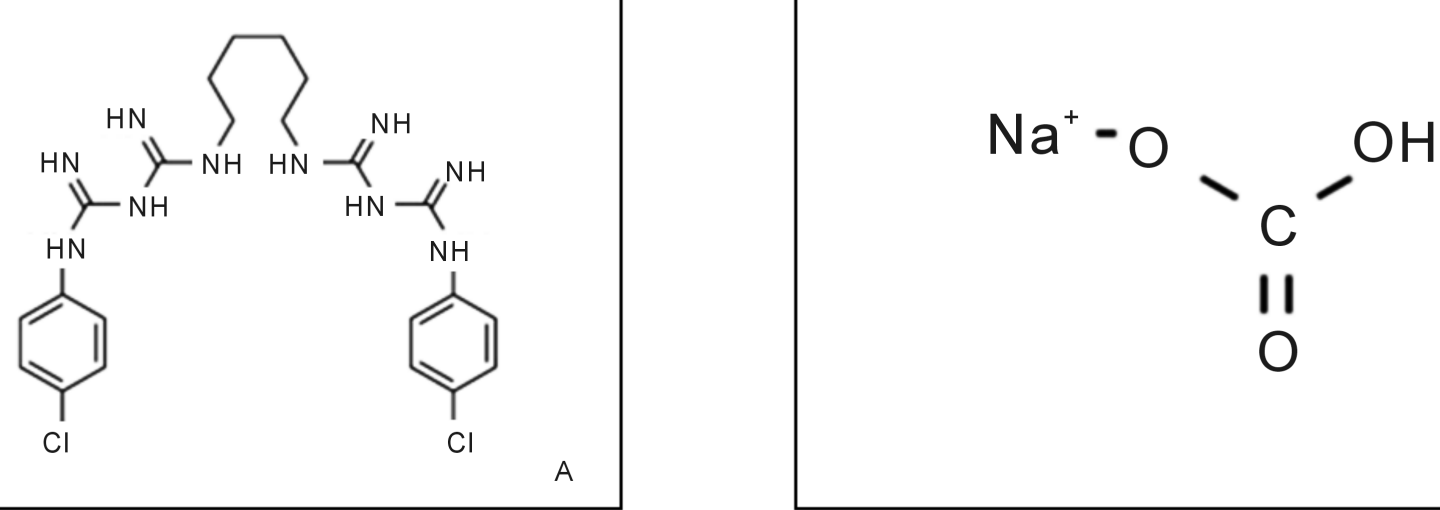

Chemical structures: chlorhexidine (A) and sodium bicarbonate (B). 
Group 2: active application of $10 \mu \mathrm{L} 2.0 \%$ chlorhexidine (FGM Dentscare LTDA; Joinville, Santa Catarina, Brazil) for 60 seconds, followed by application of Clearfil SE Bond (Kuraray Noritake Dental; Sakazu, Kurashiki, Okayama, Japan) in accordance with manufacturer instructions.

For groups 3 and 4, $200 \mathrm{mg}$ sodium bicarbonate (Biodinâmica, Ibiporã, Brazil) was diluted in $10 \mathrm{~mL}$ normal saline to obtain a $2 \%$ sodium bicarbonate solution, which was applied to the remaining caries-affected tissue.

Group 3: active application of $10 \mu \mathrm{L} 2.0 \%$ sodium bicarbonate (Biodinâmica, Ibiporã, Brazil) for 60 seconds, followed by application of Clearfil SE Bond (Kuraray Noritake Dental; Sakazu, Kurashiki, Okayama, Japan) in accordance with manufacturer instructions.

Group 4: active application of $10 \mu \mathrm{L} 2.0 \%$ sodium bicarbonate (Biodinâmica, Ibiporã, Brazil) for 60 seconds, followed by active application of $10 \mu \mathrm{L} 2.0 \%$ chlorhexidine (FGM Dentscare LTDA; Joinville, Santa Catarina, Brazil) for 60 seconds, and application of Clearfil SE Bond (Kuraray Noritake Dental; Sakazu, Kurashiki, Okayama, Japan) in accordance with manufacturer instructions.

The application and removal of excess of sodium bicarbonate and chlorhexidine were done with microbrush. The removal excess of protease inhibitors was made until the affected dentin didn't have moisture.

After application of the adhesive system, a Z350 composite resin build-up (3M ESPE, St. Paul, MN, USA) was made on the dentin surface of each specimen. Each layer of the build-up was approximately $1 \mathrm{~mm}$ thick. Layers were oriented parallel to one another and perpendicular to the long axis of the tooth, and were light-cured for 20 seconds. The intensity of the curing light (Gnatus, Ribeirão Preto, Brazil) was $1400 \mathrm{~mW} / \mathrm{cm}^{2}$, as measured by a radiometer (Curing Light, Brasília, Brazil) at the start of the experiments in each group.

Then, 10 specimens from each group were subjected to immediate microtensile bond strength testing, while the remaining 10 specimens were stored in distilled water for 6 months and then tested [28].

\subsection{Specimen Preparation}

The teeth were embedded in acrylic and wax (Kota, Cotia, Brazil). Each toothadhesive-composite block was sectioned with a diamond disk (Buehler, Illinois, USA), in parallel planes in the buccolingual direction, along the long axis of the tooth. The sections were cut sequentially along the mesiodistal plane to obtain beam-shaped specimens with a cross-sectional area of approximately $1 \mathrm{~mm}^{2}$.

Each specimen was visualized under a stereo microscope (Opton, Cotia, Brazil) at $40 \mathrm{X}$ magnification to verify that the adhesive interface was perpendicular to the long axis of the specimen.

\subsection{Microtensile Bond Strength Testing}

Before microtensile bond strength testing, the width and thickness of each specimen were measured with a digital caliper $(0.01 \mathrm{~mm}$ resolution; Mitutoyo, $\mathrm{Su}$ - 
zano, Brazil). The adhesive interface was perpendicular to the long axis of the tensile forces. The assay was performed on a universal testing machine (Instron, São José dos Pinhais, Brazil). Traction was applied to the specimen at a crosshead speed of $0.5 \mathrm{~mm} / \mathrm{min}$ until fracture occurred. At the time of fracture, the applied load in newtons $(\mathrm{N})$ was recorded and the specimen was examined under a stereo microscope at 40X magnification to ascertain the fracture mode (interface, cohesive in dentin, or cohesive in resin). Only those specimens in which adhesive/mixed-mode fracture at the interface (i.e., debonding) occurred were taken into account for calculation of bond strength. To do so, the fracture load of each specimen was divided by the bond area. Microtensile bond strength tests were performed immediately after specimen preparation and 6 months later.

For statistical analysis, the results of testing were converted from newtons to megapascals $(\mathrm{MPa})$, and each tooth was considered a distinct sampling unit. After testing, all specimens were examined under a stereo microscope (Opton, Cotia, Brazil) at $40 \mathrm{X}$ magnification to ascertain the fracture type and percentage as described by Lenzi et al. [28] Fracture mode was scored as follows:

Score 1: Adhesive/mixed-mode fracture;

Score 2: Cohesive fracture in dentin alone;

Score 3: Cohesive fracture in composite resin alone;

Score 4: Premature fracture.

For the analysis of fracture mode, each fractured stick was considered as the sampling unit.

\subsection{Statistical Analysis}

The results were analyzed in the Biostat 4.0 program. D'Agostino's test for normality revealed that the sample was nonparametric. Therefore, the KruskalWallis test followed by the Student-Newman-Keuls procedure and the MannWhitney $U$ test were used for analyses.

\section{Results}

The longevity of adhesive restorations may be compromised by the presence of metalloproteinases and chlorhexidine was described in literature with a metalloproteinases inhibitor in association with convencional adhesives systems. Sodium bicarbonate is a basic substance that can inactivate the cathepsin precursors of endogenous proteases, and could thus act as an indirect metalloproteinase inactivator. Furthermore, it is biocompatible and readily available to dental practitioners. Within this context, the present study sought to assess the influence of protease inhibitors on the bond strength of weak self-etch adhesive systems.

\subsection{Immediate}

On immediate testing, there was no significant difference in bond strength be- 
tween the control and chlorhexidine groups $(P>0.05)$. Application of sodium bicarbonate was not associated with a significant difference as compared with control, chlorhexidine only, or the combination of bicarbonate and chlorhexidine $(P>0.05)$. The combination of bicarbonate and chlorhexidine, however, led to a significant reduction in bond strength as compared with the other groups ( $P$ $<0.05$ ) (Table 2).

There were no significant differences in fracture mode across groups $(P>$ 0.05) (Table 3).

\subsection{Six Months}

At six months, bonding strength was greatest in the control group, with statistically significant differences in relation to all others $(P<0.05)$. There was no significant difference in bond strength across the bicarbonate, chlorhexidine, and bicarbonate + chlorhexidine groups $(P>0.05)$ (Table 4$)$.

There were no significant differences in fracture mode across groups $(P>$ 0.05) (Table 5).

Table 2. Median, interquartile range (IQR), arithmetic mean, standard deviation (SD), and statistical analysis (Kruskal-Wallis [KW] test with Student-Newman-Keuls procedure) of bonding strength $(\mathrm{MPa})$ immediately after specimen preparation.

\begin{tabular}{ccccc}
\hline & Control & Bicarbonate & Chlorhexidine & BIC + CLX \\
\hline Median (IQR) & $16.7(16.7) \mathrm{A}$ & $14.3(10.7) \mathrm{AB}$ & $20.3(15.1) \mathrm{A}$ & $8.3(8.3) \mathrm{B}$ \\
Mean (SD) & $19.3(11.9)$ & $15.5(8.3)$ & $21.7(16.3)$ & $12.3(11.9)$ \\
$P$-value (KW) & & \multicolumn{2}{c}{0.0337} & \\
\hline
\end{tabular}

Different letters denote $P<0.05$.

Table 3. Median, interquartile range (IQR), arithmetic mean, standard deviation (SD), and statistical analysis (Kruskal-Wallis [KW] test with Student-Newman-Keuls procedure) of fracture modes across groups immediately after specimen preparation.

\begin{tabular}{ccccc}
\hline & Control & Bicarbonate & Chlorhexidine & BIC + CLX \\
\hline Median (IQR) & $1.0(0.00) \mathrm{A}$ & $1.00(3.00) \mathrm{A}$ & $1.0(3.00) \mathrm{A}$ & $1.00(3.00) \mathrm{A}$ \\
Mean (SD) & $1.63(1.21)$ & $1.96(1.38)$ & $1.98(1.38)$ & $1.90(1.35)$ \\
$P$-value $(\mathrm{KW})$ & & \multicolumn{2}{c}{0.3270} &
\end{tabular}

Same letter denotes $P>0.05$.

Table 4. Median, interquartile range (IQR), arithmetic mean, standard deviation (SD), and statistical analysis (Kruskal-Wallis [KW] test with Student-Newman-Keuls procedure) of bonding strength $(\mathrm{MPa})$ six months after specimen preparation.

\begin{tabular}{ccccc}
\hline & Control & Bicarbonate & Chlorhexidine & BIC + CLX \\
\hline Median (IQR) & $2.5(1.4) \mathrm{A}$ & $1.3(1.1) \mathrm{B}$ & $1.3(1.6) \mathrm{B}$ & $0.9(0.7) \mathrm{B}$ \\
Mean (SD) & $2.5(1.2)$ & $1.6(1.0)$ & $1.9(1.8)$ & $1.1(1.0)$ \\
$P$-value (KW) & & \multicolumn{2}{c}{0.0035} & \\
\hline
\end{tabular}

Different letters denote $P<0.05$. 


\subsection{Comparative Analysis (Immediate vs. Six Months)}

Six months after specimen preparation, bond strength was significantly weaker across all groups $(P<0.0001)$ (Table 6).

\section{Discussion}

The contemporary restorative dentistry is based on so-called ultraconservative preparations. Removal only of infected dentin tissue, with preservation of caries-affected dentin that is still amenable to structural repair, has been advocated [27] [29]. Within this context, many studies have been conducted to evaluate the behavior of adhesive systems in caries-affected dentin [28] [30] [31] [32]. In the present study, we used the microbial method of artificial caries induction [24] [33], with bacterial strains and supplemented culture media to simulate the conditions of the oral environment. This method reproduces key characteristics of caries-affected dentin, including differences in substrate color and the presence of two distinct layers within the carious lesion (soft outer layer and harder inner layer) [34] [35]. In addition, the microbial method allows collagen degradation by bacterial esterase [36]. Chemical methods of artificial caries induction do produce demineralization of dentin to an extent capable of simulating the chemical changes that take place in caries-affected tissue, but do not elicit the biological responses observed in the natural process [37].

Table 5. Median, interquartile range (IQR), arithmetic mean, standard deviation (SD), and statistical analysis (Kruskal-Wallis [KW] test with Student-Newman-Keuls procedure) of fracture modes across groups six months after specimen preparation.

\begin{tabular}{ccccc}
\hline & Control & Bicarbonate & Chlorhexidine & BIC + CLX \\
\hline Median (IQR) & $1.00(0.00) \mathrm{A}$ & $1.00(3.00) \mathrm{A}$ & $1.00(3.00) \mathrm{A}$ & $1.00(4.00) \mathrm{A}$ \\
Mean (SD) & $1.46(0.94)$ & $1.81(1.26)$ & $1.85(1.27)$ & $1.98(1.39)$ \\
$P$-value (KW) & & \multicolumn{2}{c}{0.1056} \\
\hline
\end{tabular}

Same letter denotes $P>0.05$.

Table 6. Median, interquartile range (IQR), arithmetic mean, standard deviation (SD), and statistical analysis (Mann-Whitney test) of bonding strength (MPa) across groups.

\begin{tabular}{|c|c|c|c|c|}
\hline & \multicolumn{2}{|c|}{ Control } & \multicolumn{2}{|c|}{ Bicarbonate } \\
\hline & Before & Six months & Before & Six months \\
\hline Median (IQR) & 16.7 (16.7)A & $2.5(1.4) \mathrm{B}$ & $14.3(10.7) \mathrm{A}$ & $1.3(1.1) \mathrm{B}$ \\
\hline Mean (SD) & $19.3(11.9) \mathrm{A}$ & $2.5(1.2) \mathrm{B}$ & $15.5(8.3) \mathrm{A}$ & $1.6(1.0) \mathrm{B}$ \\
\hline \multirow[t]{3}{*}{$P$-value (Mann-Whitney) } & \multicolumn{2}{|c|}{$<0.0001$} & \multicolumn{2}{|c|}{$<0.0001$} \\
\hline & \multicolumn{2}{|c|}{ Chlorhexidine } & \multicolumn{2}{|c|}{$\mathrm{BIC}+\mathrm{CLX}$} \\
\hline & Before & Six months & Before & Six months \\
\hline Median (IQR) & $20.3(15.1) \mathrm{A}$ & $1.3(1.6) \mathrm{B}$ & $8.3(8.3) \mathrm{A}$ & $0.9(0.7) \mathrm{B}$ \\
\hline Mean (SD) & 21.7 (16.3)A & $1.5(1.8) \mathrm{B}$ & $12.3(11.9) \mathrm{A}$ & $1.1(1.0) \mathrm{B}$ \\
\hline$P$-value (Mann-Whitney) & \multicolumn{2}{|c|}{$<0.0001$} & \multicolumn{2}{|c|}{$<0.0001$} \\
\hline
\end{tabular}

Different letters denote $P<0.05$. 
When using adhesive systems that require phosphoric acid etching, inhibitors have beneficial effects on the durability of bonding to dentin, as they preserve the collagen fibers present largely in the organic dentin portion of the tooth [18] [21]. Conversely, when using self-etch adhesive systems that contain acid monomers, the effects of these inhibitors may not be beneficial [38]. The functional monomers present in self-etch adhesive systems interact with hydroxyapatite to form a chemically stable bond. In the present study, we tested the effect of two protease inhibitors alone and in combination on bonding strength to caries-affected dentin, using the two-step, self-etch Clearfil SE Bond system. The effects of matrix metalloproteinase inhibitors in adhesive interface are preservation of the collagen matrix, the enzymatic chemical bond between metalloproteinase and their inhibitors, or a combination of both mechanisms.

Kim and Shin [39] assessed the anti-Streptococcus mutans activity of one-step and two-step self-etch adhesive systems, with or without light cure, in an agar diffusion experiment. They observed zones of inhibition of bacterial growth around light-cured Clearfil SE Bond adhesive, and attributed this to the presence of residual monomer within the oxygen inhibition layer. Furthermore, they detected the functional acid monomer 10-MDP, which is capable of establishing time-stable chemical bonds with the calcium in hydroxyapatite by encapsulating denuded collagen fibers, trapping proteases in latent form within this collagen matrix [36] [40] which justifies use of the Clearfil SE Bond adhesive system on caries-affected dentin in the present study.

In our sample, pretreatment with $2 \%$ chlorhexidine or $2 \%$ sodium bicarbonate did not have an immediate negative effect on the bond strength of the Clearfil SE Bond self-etch adhesive system to caries-affected dentin. This corroborates the findings of Sacramento et al. [41] and Mobarak [31], who found that $2 \%$ chlorhexidine was not associated with reductions in immediate bond strength when the Clearfil SE Bond system was applied to carious dentin. This may be explained by the ease with which 10-MDP bonds to residual hydroxyapatite and forms stable calcium salts. In addition, applying the primer and bonding agent in separate steps increases the hydrophobicity of the adhesive layer, thus reducing water flow in the dentin tubules [42]. In a study by Lenzi et al. [43], chlorhexidine also failed to influence immediate bonding strength to caries-affected dentin in permanent teeth, using a conventional two-step adhesive system. On the other hand, Shafiei et al. [38] tested the influence of pretreatment with $2 \%$ chlorhexidine on the bond strength of two self-etch, two-bottle adhesive systems to healthy dentin. The authors found reductions in immediate bond strength of Clearfil SE Bond to healthy dentin pretreated with chlorhexidine, due to cationic bonding of chlorhexidine molecules to the phosphate and calcium in hydroxyapatite. The remaining cations bond to the phosphate anions of 10-MDP molecules. This interaction hinders binding of the 10-MDP functional acid monomer to dentin calcium, thus weakening the bond to dentin.

In the present study, pretreatment of caries-affected dentin with $2 \%$ sodium bicarbonate did not interfere with the immediate bond strength of the Clearfil 
SE Bond system. This may be explained by the lack of any immediate interference of sodium bicarbonate with the effects of the functional acid monomer or with the organic acids present in the primer. Another hypothesis is incorporation of sodium bicarbonate particles into the hybrid layer and smear layer [44]. However, the combination of $2 \%$ sodium bicarbonate and $2 \%$ chlorhexidine led to an immediate reduction in microtensile bond strength. Possible explanations for this phenomenon include a negative interaction of these two solutions when mixed together, or excessive moisture on the dentin surface caused by consecutive application of the two solutions. The hydrophobic monomer of Clearfil SE Bond adhesive is rendered unable to diffuse into the substrate; instead, globules form in the aqueous environment, preventing infiltration of the bonding agent and its adherence to the caries-affected dentin [44].

After 6 months, bond strength was diminished in all groups. This disagrees with the findings of Gunaydin et al. [45]. One possible explanation for the increased bond strength in the group not treated with any protease inhibitor is that the 10-MDP functional acid monomer present in Clearfil SE Bond may have bound more strongly to the calcium ions in hydroxyapatite crystals. Application of this weak self-etch adhesive system alone allowed hydroxyapatite to remain around the collagen fibers, thus "fossilizing" proteolytic enzymes. Collagen degradation was mitigated, and the hybrid layer was preserved [40]. In groups pretreated with $2 \%$ chlorhexidine, sodium bicarbonate, or a combination of the two, bond strength declined to a greater extent than in the control group. This may be explained by these substances acting as contaminants on the dentin surface, interfering with proper hybridization of dentin tissue with the self-etch adhesive system, which has simultaneous demineralizing and infiltrating action. In addition, specimens were stored in water for 6 months and were thus exposed to hydrolysis of the adhesive interface and collagen degradation in the hybrid layer, which may have led to a breakdown in the adhesive bond [46].

A high rate of premature fracture was observed in all groups, both immediately after specimen preparation and after 6 months. This may be attributed to the low cohesive strength of caries-affected dentin, and is consistent with the findings of Yoshiyama et al. [47] and Lenzi et al. [36]. In all groups, the predominant fracture mode was adhesive/mixed. This may be explained by the chemical interaction of the adhesive system with the hydroxyapatite present in dentin, forming a bond that is stronger than the dentin or composite resin substrates themselves [48].

Taking into account the limitations inherent to an in vitro experiment, the present study demonstrated that there is no place for protease inhibitors during adhesive restorations performed with composite resin and the Clearfil SE Bond adhesive system. Further studies in a similar line of research are needed to contribute to the evidence base on this topic.

\section{Conclusion}

Cavity pretreatment with the protease inhibitors $2 \%$ chlorhexidine or sodium 
bicarbonate did not have an immediate negative impact on bond strength of the Clearfil SE Bond system. At 6 months, however, bond strength was reduced in all groups. This reduction was the greatest in the groups exposed to the inhibitors.

\section{Financial Disclosure}

The authors have no financial relationships relevant to this article to disclose.

\section{Conflict of Interest}

The authors have no conflicts of interest to disclose.

\section{References}

[1] van Strijp, A.J., van Steenbergen, T.J., de Graaff, J. and ten Cate, J.M. (1994) Bacterial Colonization and Degradation of Demineralized Dentin Matrix in Situ. Caries Research, 28, 21-27. https://doi.org/10.1159/000261615

[2] Tjaderhane, L., Larjava, H., Sorsa, T., Uitto, V.J., Larmas, M. and Salo, T. (1998) The Activation and Function of Host Matrix Metalloproteinases in Dentin Matrix Breakdown in Caries Lesions. Journal of Dental Research, 77, 1622-1629. https://doi.org/10.1177/00220345980770081001

[3] Hebling, J., Pashley, D.H., Tjaderhane, L. and Tay, F.R. (2005) Chlorhexidine Arrests Subclinical Degradation of Dentin Hybrid Layers in Vivo. Journal of Dental Research, 84, 741-746. https://doi.org/10.1177/154405910508400811

[4] Pinheiro, S.L., Frasson, A.D., Bincelli, I.N., Barros, P.P. and Silva, G.H. (2008) Study of a Morphometric Model for Histological Evaluation of the Collagen in Dentin Carious Lesions. Journal of Clinical Pediatric Dentistry, 33, 123-126. https://doi.org/10.17796/jcpd.33.2.d27n643xg5532704

[5] Pinheiro, S.L., Gallassi, P.C., Saldanha, T.C., Bincelli, I.N., Barros, P.P. and Silva, G.H. (2010) Repairing Collagen in Dentin Carious Lesions. Influence of Sealing the Material: A Morphometric Study. Journal of Clinical Pediatric Dentistry, 34, 223 228. https://doi.org/10.17796/jcpd.34.3.ut5444720r61375h

[6] Martin-De Las Heras, S., Valenzuela, A. and Overall, C.M. (2000) The Matrix Metalloproteinase Gelatinase A in Human Dentine. Archives of Oral Biology, 45, 757 765. https://doi.org/10.1016/S0003-9969(00)00052-2

[7] Sulkala, M., Larmas, M., Sorsa, T., Salo, T. and Tjäderhane, L. (2002) The Localization of Matrix Metalloproteinase-20 (MMP-20, Enamelysin) in Mature Human Teeth. Journal of Dental Research, 81, 603-607.

https://doi.org/10.1177/154405910208100905

[8] Sulkala, M., Tervahartiala, T., Sorsa, T., Larmas, M., Salo, T. and Tjäderhane, L. (2007) Matrix Metalloproteinase-8 (MMP-8) Is the Major Collagenase in Human Dentin. Archives of Oral Biology, 52, 121-127.

https://doi.org/10.1016/j.archoralbio.2006.08.009

[9] Mazzoni, A., Mannello, F., Tay, F.R., Tonti, G.A., Papa, S., Mazzotti, G., Di Lenarda, R., Pashley, D.H. and Breschi, L. (2007) Zymographic Analysis and Characterization of MMP-2 and 9 Forms in Human Sound Dentin. Journal of Dental Research, 86, 436-440. https://doi.org/10.1177/154405910708600509

[10] Nascimento, F.D., Minciotti, C.L., Geraldeli, S., Carrilho, M.R., Pashley, D.H., Tay, F.R., Nader, H.B., Salo, T., Tjäderhane, L. and Tersariol, I.L. (2011) Cysteine Ca- 
thepsins in Human Carious Dentin. Journal of Dental Research, 90, 506-511. https://doi.org/10.1177/0022034510391906

[11] Mazzoni, A., Tjaderhane, L., Checchi, V., Di Lenarda, R., Salo, T., Tay, F.R., Pashley, D.H. and Breschi, L. (2015) Role of Dentin MMPs in Caries Progression and Bond Stability. Journal Dental Research, 94, 241-251. https://doi.org/10.1177/0022034514562833

[12] Alex, G. (2015) Universal Adhesives: The Next Evolution in Adhesive Dentistry? Compendium of Continuing Education in Dentistry, 36, 15-26.

[13] Gendron, R., Grenier, D., Sorsa, T. and Mayrand, D. (1999) Inhibition of the Activities of Matrix Metalloproteinases 2, 8, and 9 by Chlorhexidine. Clinical and Diagnostic Laboratory Immunology, 6, 437-439.

[14] Thompson, J.M., Agee, K., Sidow, S.J., McNally, K., Lindsey, K., Borke, J., Elsalanty, M., Tay, F.R. and Pashley, D.H. (2012) Inhibition of Endogenous Dentin Matrix Metalloproteinases by Ethylenediaminetetraacetic Acid. Journal of Endodontic, 38, 62-65. https://doi.org/10.1016/j.joen.2011.09.005

[15] Demeule, M., Brossard, M., Page, M., Gingras, D. and Béliveau, R. (2000) Matrix Metalloproteinase Inhibition by Green Tea Catechins. Biochimica et Biophysica Acta, 1478, 51-60. https://doi.org/10.1016/S0167-4838(00)00009-1

[16] Yang, H., Guo, J., Deng, D., Chen, Z. and Huang, C. (2016) Effect of Adjunctive Application of Epigallocatechin-3-Gallate and Ethanol-Wet Bonding on AdhesiveDentin Bonds. Journal of Dentistry, 44, 44-49. https://doi.org/10.1016/j.jdent.2015.12.001

[17] Robey, I.F. and Nesbit, L.A. (2013) Investigating Mechanisms of Alkalinization for Reducing Primary Breast Tumor Invasion. Biomedical Research International, 2013, Article ID: 485196. https://doi.org/10.1155/2013/485196

[18] Van Landuyt, K.L., Yoshida, Y., Hirata, I., Snauwaert, J., De Munck, J., Okazaki, M., Suzuki, K., Lambrechts, P. and Van Meerbeek, B. (2008) Influence of the Chemical Structure of Functional Monomers on Their Adhesive Performance. Journal Dental Research, 87, 757-761. https://doi.org/10.1177/154405910808700804

[19] Van Meerbeek, B., Yoshihara, K., Yoshida, Y., Mine, A., De Munck, J. and Van Landuyt, K.L. (2011) State of the Art of Self-Etch Adhesives. Dental Materials, 27, 17-28. https://doi.org/10.1016/j.dental.2010.10.023

[20] Marchesi, G., Frassetto, A., Mazzoni, A., Apolonio, F., Diolosà, M., Cadenaro, M., Di Lenarda, R., Pashley, D.H., Tay, F. and Breschi, L. (2014) Adhesive Performance of a Multi-Mode Adhesive System: 1-Year in Vitro Study. Journal of Dentistry, 42, 603-612. https://doi.org/10.1016/j.jdent.2013.12.008

[21] Perdigão, J., Reis, A. and Loguercio, A.D. (2013) Dentin Adhesion and MMPs: A Comprehensive Review. Journal of Esthetic and Restorative Dentistry, 25, 219-241. https://doi.org/10.1111/jerd.12016

[22] Tsujimoto, A., Iwasa, M., Shimamura, Y., Murayama, R., Takamizawa, T. and Miyazaki, M. (2010) Enamel Bonding of Single-Step Self-Etch Adhesives: Influence of Surface Energy Characteristics. Journal of Dentistry, 38, 123-130. https://doi.org/10.1016/j.jdent.2009.09.011

[23] Islam, M.S., Hiraishi, N., Nassar, M., Yiu, C., Otsuki, M. and Tagami, J. (2014) Effect of Hesperidin Incorporation into a Self-Etching Primer on Durability of Dentin Bond. Dental Materials, 30, 1205-1212. https://doi.org/10.1016/j.dental.2014.08.371

[24] de Carvalho, F.G., de Fucio, S.B., Sinhoreti, M.A., Correr-Sobrinho, L. and PuppinRontani, R.M. (2008) Confocal Laser Scanning Microscopic Analysis of the Depth of Dentin Caries-Like Lesions in Primary and Permanent Teeth. Brazilian Dental 
Journal, 19, 139-144. https://doi.org/10.1590/S0103-64402008000200010

[25] Banerjee, A., Watson, T.F. and Kidd, E.A. (2000) Dentine Caries Excavation: A Review of Current Clinical Techniques. British Dental Journal, 188, 476-482. https://doi.org/10.1038/sj.bdj.4800515a

[26] Schwendicke, F., Dorfer, C.E. and Paris, S. (2013) Incomplete Caries Removal: A Systematic Review and Meta-Analysis. Journal Dental Research, 92, 306-314. https://doi.org/10.1177/0022034513477425

[27] Schwendicke, F., Eggers, K., Lueckel-Meyer, H., Dörfer, C., Kovalev, A., Gorb, S. and Paris, S. (2015) In Vitro Induction of Residual Caries Lesions in Dentin: Comparative Mineral Loss and Nano-Hardness Analysis. Caries Research, 49, 259-265. https://doi.org/10.1159/000371897

[28] Lenzi, T.L., Raggio, D.P., Soares, F.Z. and Rocha, R.O. (2015) Bonding Performance of a Multimode Adhesive to Artificially-Induced Caries-Affected Primary Dentin. The Journal of Adhesive Dentistry, 17, 125-131.

[29] Sirin Karaarslan, E., Yildiz, E., Cebe, M.A., Yegin, Z. and Ozturk, B. (2012) Evaluation of Micro-Tensile Bond Strength of Caries-Affected Human Dentine after Three Different Caries Removal Techniques. Journal of Dentistry, 40, 793-801. https://doi.org/10.1016/j.jdent.2012.05.013

[30] Nishitani, Y., Yoshiyama, M., Tay, F.R., Wadgaonkar, B., Waller, J., Agee, K. and Pashley, D.H. (2005) Tensile Strength of Mineralized/Demineralized Human Normal and Carious Dentin. Journal of Dental Research, 84, 1075-1078. https://doi.org/10.1177/154405910508401121

[31] Mobarak, E.H. (2011) Effect of Chlorhexidine Pretreatment on Bond Strength Durability of Caries-Affected Dentin over 2-Year Aging in Artificial Saliva and under Simulated Intrapulpal Pressure. Operative Dentistry, 36, 649-660. https://doi.org/10.2341/11-018-L

[32] Bahari, M., Savadi Oskoee, S., Kimyai, S., Pouralibaba, F., Farhadi, F. and Norouzi, M. (2014) Effect of Casein Phosphopeptide-Amorphous Calcium Phosphate Treatment on Microtensile Bond Strength to Carious Affected Dentin using Two Adhesive Strategies. Journal of Dental Research, Dental Clinics, Dental Prospects, 8, 141147.

[33] Sanabe, M.E., Costa, C.A. and Hebling, J. (2011) Exposed Collagen in Aged ResinDentin Bonds Produced on Sound and Caries-Affected Dentin in the Presence of Chlorhexidine. The Journal of Adhesive Dentistry, 13, 117-124.

[34] Clarkson, B.H., Wefel, J.S. and Miller, I. (1984) A Model for Producing Caries-Like Lesions in Enamel and Dentin using Oral Bacteria in Vitro. Journal of Dental Research, 63, 1186-1189. https://doi.org/10.1177/00220345840630100201

[35] Momoi, Y., Hayashi, M., Fujitani, M., Fukushima, M., Imazato, S., Kubo, S., Nikaido, T., Shimizu, A., Unemori, M. and Yamaki, C. (2012) Clinical Guidelines for Treating Caries in Adults Following a Minimal Intervention Policy-Evidence and Consensus Based Report. Journal of Dentistry, 40, 95-105. https://doi.org/10.1016/j.jdent.2011.10.011

[36] Lenzi, T.L., Tedesco, T.K., Calvo, A.F., Ricci, H.A., Hebling, J. and Raggio, D.P. (2014) Does the Method of Caries Induction Influence the Bond Strength to Dentin of Primary Teeth? The Journal of Adhesive Dentistry, 16, 333-338.

[37] Marquezan, M., Correa, F.N., Sanabe, M.E., Rodrigues Filho, L.E., Hebling, J., Guedes-Pinto, A.C. and Mendes, F.M. (2009) Artificial Methods of Dentine Caries Induction: A Hardness and Morphological Comparative Study. Archives of Oral Biology, 54, 1111-1117. https://doi.org/10.1016/j.archoralbio.2009.09.007 
[38] Shafiei, F., Alikhani, A. and Alavi, A.A. (2013) Effect of Chlorhexidine on Bonding Durability of Two Self-Etching Adhesives with and without Antibacterial Agent to Dentin. Dental Research Journal (Isfahan), 10, 795-801.

[39] Kim, S.R. and Shin, D.H. (2014) Antibacterial Effect of Self-Etching Adhesive Systems on Streptococcus mutans. Restorative Dentistry \& Endodontics, 39, 32-38. https://doi.org/10.5395/rde.2014.39.1.32

[40] Tjaderhane, L., Nascimento, F.D., Breschi, L., Mazzoni, A., Tersariol, I.L., Geraldeli, S., Tezvergil-Mutluay, A., Carrilho, M., Carvalho, R.M., Tay, F.R. and Pashley, D.H. (2013) Strategies to Prevent Hydrolytic Degradation of the Hybrid Layer-A Review. Dental Materials, 29, 999-1011. https://doi.org/10.1016/j.dental.2013.07.016

[41] Sacramento, P.A., de Castilho, A.R., Banzi, E.C. and Puppi-Rontani, R.M. (2012) Influence of Cavity Disinfectant and Adhesive Systems on the Bonding Procedure in Demineralized Dentin-A One-Year in Vitro Evaluation. The Journal of Adhesive Dentistry, 14, 575-583.

[42] Schwendicke, F., Kern, M., Dörfer, C., Kleemann-Lüpkes, J., Paris, S. and Blunck, U. (2015) Influence of Using Different Bonding Systems and Composites on the Margin Integrity and the Mechanical Properties of Selectively Excavated Teeth in Vitro. Journal of Dentistry, 43, 327-334. https://doi.org/10.1016/j.jdent.2014.12.014

[43] Lenzi, T.L., Tedesco, T.K., Soares, F.Z., Loguercio, A.D. and Rocha Rde, O. (2012) Chlorhexidine Does Not Increase Immediate Bond Strength of Etch-and-Rinse Adhesive to Caries-Affected Dentin of Primary and Permanent Teeth. Brazilian Dental Journal, 23, 438-442. https://doi.org/10.1590/S0103-64402012000400022

[44] Rosin, C., Arana-Chavez, V.E., Netto, N.G. and Luz, M.A. (2005) Effects of Cleaning Agents on Bond Strength to Dentin. Brazilian Oral Research, 19, 127-133. https://doi.org/10.1590/S1806-83242005000200010

[45] Gunaydin, Z., Yazici, A.R. and Cehreli, Z.C. (2016) In Vivo and In Vitro Effects of Chlorhexidine Pretreatment on Immediate and Aged Dentin Bond Strengths. Operative Dentistry, 41, 258-267. https://doi.org/10.2341/14-231-C

[46] Zheng, P., Zaruba, M., Attin, T. and Wiegand, A. (2015) Effect of Different Matrix Metalloproteinase Inhibitors on Microtensile Bond Strength of an Etch-and-Rinse and a Self-Etching Adhesive to Dentin. Operative Dentistry, 40, 80-86.

https://doi.org/10.2341/13-162-L

[47] Yoshiyama, M., Tay, F.R., Doi, J., Nishitani, Y., Yamada, T., Itou, K., Carvalho, R.M., Nakajima, M. and Pashley, D.H. (2002) Bonding of Self-Etch and Total-Etch Adhesives to Carious Dentin. Journal of Dental Research, 81, 556-560. https://doi.org/10.1177/154405910208100811

[48] de Goes, M.F., Shinohara, M.S. and Freitas, M.S. (2014) Performance of a New OneStep Multi-Mode Adhesive on Etched vs. Non-Etched Enamel on Bond Strength and Interfacial Morphology. The Journal of Adhesive Dentistry, 16, 243-250. 